\title{
Humoral immune response and delayed type hypersensitivity to influenza vaccine in patients with diabetes mellitus
}

\author{
R. J.A. Diepersloot ${ }^{1}$, K.P. Bouter ${ }^{2}$, W.E.P. Beyer ${ }^{1}$, J.B. L. Hoekstra ${ }^{2}$ and N. Masurel ${ }^{1}$ \\ ${ }^{1}$ Department of Virology and WHO Influenza Centre, University Hospital Dijkzigt, Rotterdam, and \\ ${ }^{2}$ Department of Internal Medicine, Diakonessen Hospital, Utrecht, The Netherlands
}

\begin{abstract}
Summary. The antibody response and delayed type hypersensitivity reaction to commercially available trivalent influenza vaccine in 159 patients with diabetes mellitus was compared with response and reaction in 28 healthy volunteers. A correction for prevaccination titres was made. No differences were found between diabetic patients and control subjects with respect to antibody response to the three vaccine strains as measured by the difference between geometric mean titres of post- and prevaccination sera. In Type 1 (insulin-dependent) diabetic patients the incidence of non-responders to two vaccine components was significantly increased $(p<$
\end{abstract}

$0.05)$. The delayed type hypersensitivity reaction to influenza antigen was significantly decreased in patients with high concentrations of glycosylated haemoglobin $(p<0.01)$. These findings suggest a role for impaired immune response in the increased influenza morbidity and mortality in patients with diabetes mellitus. Implications for therapy and vaccination strategy are discussed.

Key words: Diabetes mellitus, influenza, delayed type hypersensitivity, vaccination, immunity.
Infections with influenza carry a high morbidity and mortality rate in patients with diabetes mellitus [1-3]. The increased risk of complications in these patients is generally ascribed to the occurrence of diabetic ketoacidosis [4] and secondary bacterial infection, mainly by Staphylococcus aureus [5]. Patients with diabetes mellitus are often carriers of Staphylococcus aureus, and they have been shown to have an impaired immune response to this micro-organism $[6,7]$.

In order to prevent these complications, annual vaccination of diabetic patients is recommended. To accomplish protection against influenza, vaccination should induce high antibody titres against the viral haemagglutinin [8]. Simultaneously stimulated cellular immunity, though not protective, might contribute to the recovery from infections with influenza viruses [9].

Poor antibody response to influenza vaccination has been demonstrated in various risk groups, such as renal transplant patients [10], patients with malignant diseases [11, 12] and in the aged [13].

In order to evaluate the immune response to influenza antigen in both Type 1 (insulin-dependent) and Type 2 (non-insulin-dependent) diabetic patients, we studied the antibody production and delayed type hypersensitivity reaction after vaccination with a trivalent influenza vaccine.

\section{Subjects and methods}

\section{Subjects}

Patients studied were attending the outpatient clinic of the Department of Internal Medicine of the Diakonessen Hospital, Utrecht, The Netherlands. Patients were considered to be Type 1 if there had been documented ketoacidosis and/or abrupt onset of symptoms requiring insulin therapy at age $<40$ years and Type 2 if there had been protracted treatment with diet or oral therapy at age $>40$ years. The study population consisted of 27 patients with Type 1 diabetes mellitus, 18 men and 9 women (mean age $39.3 \pm 13.6$ years, mean duration of disease $16.5 \pm 14.0$ years) and 120 patients with Type 2 diabetes mellitus, 51 men and 69 women (mean age $65.3 \pm 10.0$ years, mean duration of disease $10.3 \pm 7.1$ years). Among 12 patients, 5 men and 7 women (mean age $61.9 \pm 7.4$ years), the type of diabetes was unknown. In Type 1 diabetic patients, 5 had known cardiovascular complications, 3 were treated for retinopathy and 1 had marked neuropathy. Among Type 2 patients 37\% were more than $10 \%$ overweight and $25 \%$ had major cardiovascular complications. Retinopathy was diagnosed in 16 and neuropathy in 13\% of Type 2 diabetic patients. Control subjects were 28 healthy volunteers, 13 men and 15 women (mean age $50.8 \pm 17.0$ years). Participants were excluded if they were allergic to egg protein or when febrile on the day of vaccination. Written consent was obtained from all participants and approval for the study was obtained from the Ethical Committee of the University Hospital Dijkzigt.

\section{Vaccine: dosage and administration}

Trivalent purified whole virus influenza vaccine (Duphar-Nederland, Amsterdam, The Netherlands) containing $10 \mu \mathrm{g}$ haemagglutinin 
(HA) A/Philippines/2/82 (H3N2), 10 ug HA A/Chile/1/83 (H1N1) and $15 \mu \mathrm{g} \mathrm{HA} \mathrm{B} / \mathrm{USSR} / 100 / 83$ was administered in $0.5 \mathrm{ml}$ doses intramuscularly in the upper arm. To induce a delayed type hypersensitivity reaction, an $0.1 \mathrm{ml}$ dose of the same vaccine (diluted $1: 1$ with phosphate buffered saline) was inoculated into the skin of the volar aspect of the forearm.

\section{Laboratory investigations and calculations}

Blood samples were obtained prior to administration of vaccine and again 14 days later. Sera were separated immediately after blood collection and clotting and stored at $-20^{\circ} \mathrm{C}$ until titration.

Influenza strains were propagated in embryonated hen's eggs. Because of the low avidity of the influenza B virus, infectious egg fluids of this strain were treated with aether according to Berlin et al. [14] and the watery phase was used in the serologic tests.

Serum haemagglutination inhibition (HI) titres were determined twice by standard methods [15] simultaneously in pre- and post-vaccination sera. Titres were expressed as reciprocals of the dilution showing $50 \%$ haemagglutination inhibition with 3 haemagglutination units of the antigen. From the results of the two determinations per serum and per antigen, the geometric means were used for further calculations. Negative titres $(<9)$ were arbitrarily regarded as 5.

With the method used, protection against influenza is thought to be associated with an HI titre of 100 for influenza A [8]. No protection threshold is known for aether-treated influenza B strains. For this study an HI titre of 100 was assumed to be protective.

Among diabetic patients and control subjects, those with prevaccination titres above 100 were excluded separately for each antigen. The serologic response upon vaccination was expressed using the following criteria: the response rate (i. e. the proportion of subjects with a 4 -fold or greater titre increase after vaccination); the protection rate (i.e. the proportion of subjects exceeding the threshold titre of 100 after vaccination); the mean-fold increase (i.e. the difference between the logarithmated geometric mean titres of post- and prevaccination sera).

\section{Glycosylated haemoglobin}

The percentage of glycosylated haemoglobin $\left(\mathrm{HbA}_{1 \mathrm{c}}\right)$ on the day of vaccination was determined by a commercially available column test (Bio Rad Laboratories, Richmond, Calif, USA). In short, a small quantity of whole blood is mixed with a haemolysis reagent. An aliquot of the haemolysate is then applied to a weakly acidic cation exchange resin in a disposable column. The $\mathrm{HbA}_{1 \mathrm{a}}$ and $\mathrm{HbA}_{1 \mathrm{~b}}$ fractions are first eluted by adding a buffer. The $\mathrm{HbA}_{1 \mathrm{c}}$ fraction is then eluted separately by adding a second dilution/developing reagent. The relative $\%$ concentration of $\mathrm{HbA}_{1 \mathrm{c}}$ is determined spectrophotometrically.

\section{Delayed type hypersensitivity reaction (DTHR)}

DFHR was read after $24 \mathrm{~h}$. Quantification of the test was achieved by calculating the area of induration as the product of two diameters at right angles. Diameters were measured as described previously by Sokal [17].

\section{Statistical analysis}

Data are presented as mean $\pm \mathrm{SD}$. Differences in qualitative measures were tested for significance by the chi-square test, and in quantitative measures by the Wilcoxon rank test.

\section{Results}

\section{Seroresponse}

The outcome of the serologic determinations was calculated for type of diabetes mellitus and for the thera- peutic regimen. Results are presented for the three vaccine strains separately in Tables $1-3$. Although patients with Type 1 diabetes and those with Type 2 diabetes treated with a diet only tended to have lower antibody responses after vaccination as compared to control subjects, differences in mean-fold increase were not statistically significant. The established protection rate was high for the H3N2 strain (Table 1), reaching 90\% in control subjects and $85 \%$ in diabetic patients. Protection rates for the other two vaccine components, however, were considerably lower: 66 and $64 \%$ for $\mathrm{H} 1 \mathrm{~N} 1$ and 50 and 57\% for the influenza B strain (control subjects and patients, respectively). Differences were not statistically significant.

In comparison with control subjects, the incidence of patients showing a 4-fold or greater titre rise was substantially lower in Type 1 diabetes for the $\mathrm{H} 3 \mathrm{~N} 2$ and influenza $B$ vaccine components (100 vs $78 \%$ and 80 vs $44 \%$, respectively, $p<0.05$ ). A significantly lower incidence of patients with a 4-fold or greater titre increase to the influenza $B$ strain was also shown for patients treated with insulin, a major part of whom had Type 1 diabetes (46 vs $80 \%$ in control subjects, $p<$ 0.01 ).

For patients treated with diet only, the incidence of patients with a 4-fold or greater titre increase was significantly lower for the $\mathrm{H} 3 \mathrm{~N} 2$ component (78 vs $100 \%$ in control subjects, $p<0.05)$. There was no correlation between antibody production or response rate and the concentration of $\mathrm{HbA}_{1 \mathrm{c}}$.

\section{Delayed type hypersensitivity reaction (DTHR)}

In order to establish a correlation between the DTHR and the metabolic state, all 159 patients were divided into two groups according to the concentration of glycosylated haemoglobin: $\mathrm{HbA}_{1 \mathrm{c}} 4-6.5 \%$ (within normal limits), and $>6.5 \%$.

The largest induration was demonstrated in control subjects: $360 \mathrm{~mm}^{2}( \pm 246)$. In patients with $\mathrm{HbA}_{1}$ values within normal limits $\left(\mathrm{HbA}_{1} \leq 6.5 \%\right)$, the DTHR was similar to that in control subjects. In comparison with control subjects, the DTHR in patients with an $\mathrm{HbA}_{1 \mathrm{c}}>6.5 \%$ was significantly decreased $(p<0.01)$. Results are shown in Figure 1.

\section{Discussion}

From a previous study it was concluded that patients with well controlled diabetes mellitus respond normally to influenza immunisation. The population studied, however, was small and prevaccination titres were considerably higher in control subjects, for which no correction was made [18]. In the present study a correction was included for prevaccination titres. It is shown that, at least in patients with Type 1 diabetes, there is an increased incidence of non-responders to two of the three vaccine components. Humoral immune response 
Table 1. Serologic response to the H3N2 vaccine component in control subjects and in patients with diabetes mellitus

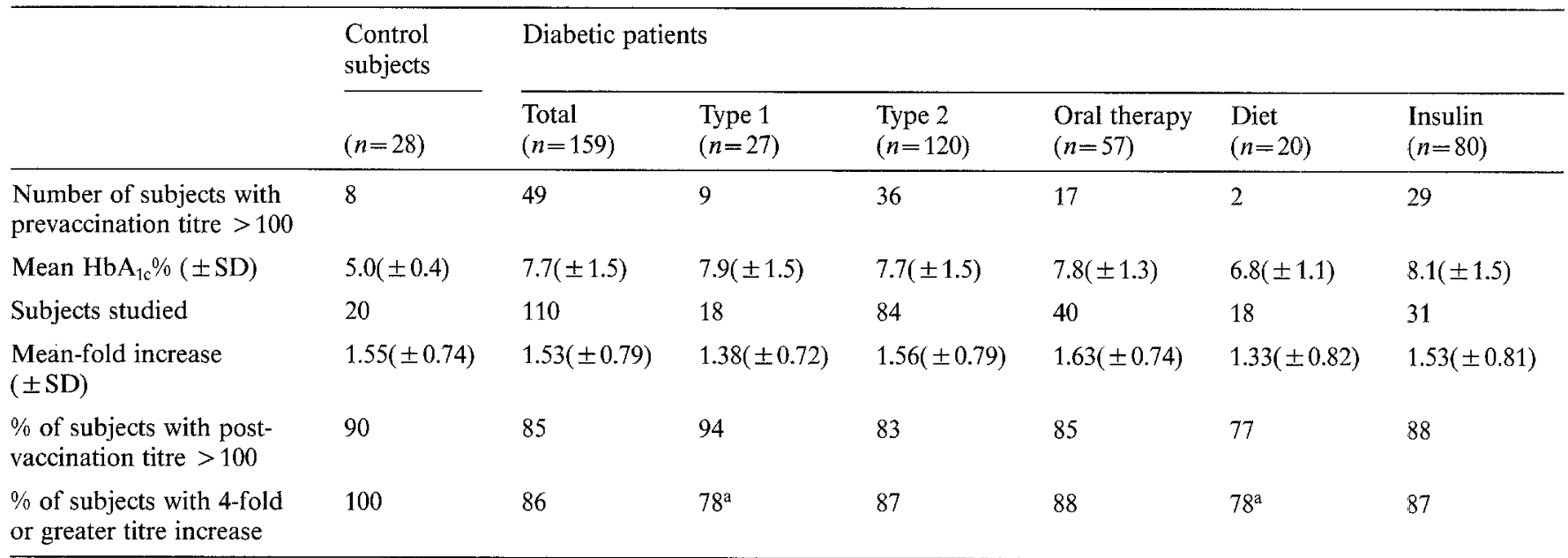

Data of 12 patients whose type of diabetes was unknown and of 2 patients with both insulin and oral therapy are not shown. ${ }^{a}$ Different from controls $p<0.05$

Table 2. Serologic response to the H1N1 vaccine component in control subjects and in patients with diabetes mellitus

\begin{tabular}{|c|c|c|c|c|c|c|c|}
\hline & \multirow{2}{*}{$\begin{array}{l}\text { Control } \\
\text { subjects }\end{array}$} & \multicolumn{6}{|c|}{ Diabetic patients } \\
\hline & & $\begin{array}{l}\text { Total } \\
(n=159)\end{array}$ & $\begin{array}{l}\text { Type } 1 \\
(n=27)\end{array}$ & $\begin{array}{l}\text { Type } 2 \\
(n=120)\end{array}$ & $\begin{array}{l}\text { Oral therapy } \\
(n=57)\end{array}$ & $\begin{array}{l}\text { Diet } \\
(n=20)\end{array}$ & $\begin{array}{l}\text { Insulin } \\
(n=80)\end{array}$ \\
\hline $\begin{array}{l}\text { Number of subjects with } \\
\text { prevaccination titre }>100\end{array}$ & 4 & 14 & 4 & 8 & 6 & 1 & 7 \\
\hline Mean $\mathrm{HbA}_{\mathrm{tc}} \%( \pm \mathrm{SD})$ & $5.0( \pm 0.5)$ & $7.7( \pm 1.5)$ & $7.5( \pm 1.6)$ & $7.8( \pm 1.5)$ & $7.9( \pm 1.4)$ & $6.6( \pm 1.1)$ & $8.1( \pm 1.6)$ \\
\hline $\begin{array}{l}\text { Mean-fold increase } \\
( \pm S D)\end{array}$ & $1.04( \pm 0.61)$ & $1.04( \pm 0.68)$ & $1.07( \pm 0.67)$ & $1.04( \pm 0.68)$ & $1.17( \pm 0.61)$ & $0.79( \pm 0.62)$ & $1.00( \pm 0.63)$ \\
\hline $\begin{array}{l}\% \text { of subjects with post- } \\
\text { vaccination titre }>100\end{array}$ & 66 & 64 & 73 & 62 & 70 & 47 & 64 \\
\hline $\begin{array}{l}\% \text { of subjects with } 4 \text {-fold } \\
\text { or greater titre increase }\end{array}$ & 67 & 65 & 70 & 67 & 69 & 58 & 58 \\
\hline
\end{tabular}

Data of 12 patients whose type of diabetes was unknown and of 2 patients with both insulin and oral therapy are not shown

Table 3. Serologic response to the influenza B vaccine component in control subjects and in patients with diabetes mellitus

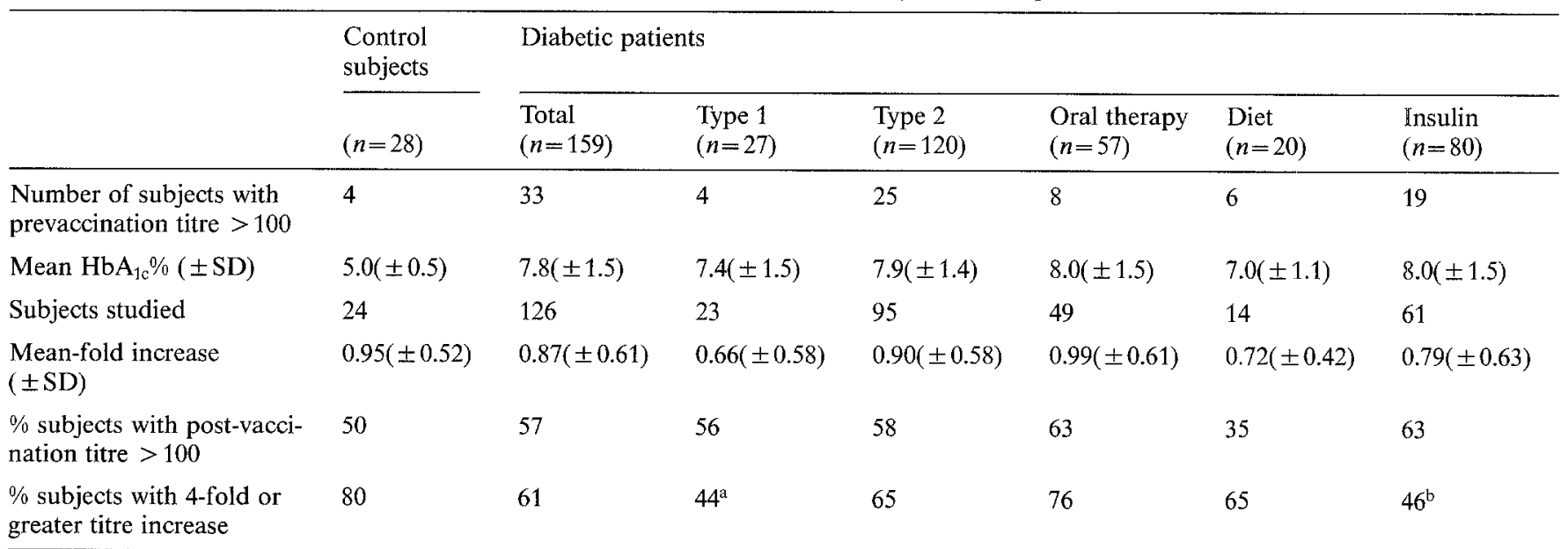

Data of 12 patients whose type of diabetes was unknown and of 2 patients with both insulin and oral therapy are not shown. ${ }^{a}$ Different from control subjects $p<0.05 ;{ }^{b} p<0.01$ 


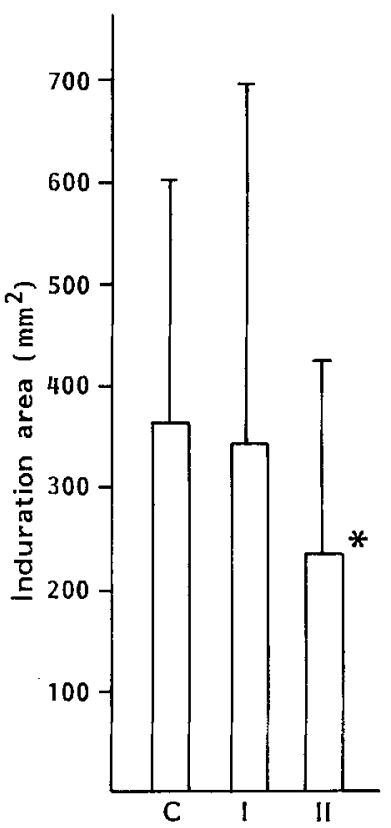

Fig. 1. Mean area of induration after inoculation of influenza vaccine in healthy control subjects (C) and in patients with diabetes mellitus. Patients were arbitrarily divided into two groups according to the percentage of $\mathrm{HbA}_{1 \mathrm{c}}$ : group I, 4-6.5\% $(n=35)$; group II, $>$ $6.5 \%(n=159) . *$ different from control subjects, $p<0.01$

to influenza vaccination has been shown to be impaired in the elderly [13]; however, as control subjects (mean age $50.8 \pm 17.0$ years) were older than Type 1 diabetic patients (mean age $34.4 \pm 13.6$ years), age cannot be held responsible for the increased incidence of non-responders among Type 1 patients.

Antibody formation against the influenza antigen is a T-cell dependent phenomenon. In experimental animals the humoral immune response is impaired if the helper effect of T cells is lacking [19]. In patients with Type 1 diabetes, T-cell depletion has recently been demonstrated [20]. This may explain the increased incidence of non-responders to influenza antigen, while antibody response to pneumococcal polysaccharide, which may proceed independently of T-cell help, is not decreased [21].

The number of patients unable to acquire a protective antibody level against the influenza B and H1N1 vaccine components is substantial. This is an important outcome, considering the high incidence of other risk factors such as cardiovascular diseases, especially in elderly diabetic patients. Barker and Mullooly [1] showed that influenza mortality is highest in patients who have cardiovascular disease in combination with either diabetes or chronic pulmonary disease. Therefore, a booster immunisation after at least 4 weeks seems to be advisable in patients with diabetes mellitus. However, results of booster vaccination in other risk groups are disappointing [10, 22].

Decreased DTHR to candida in diabetic patients has been previously demonstrated [23]. In the same study no decreased DTHR was found for a viral antigen (mumps). Mahmoud et al. [24] showed that decreased cellular hypersensitivity in diabetic mice could be restored with insulin treatment. Our findings of a decreased DTHR in patients with high $\mathrm{HbA}_{1 \mathrm{c}}$ values and not in patients with $\mathrm{HbA}_{1 \mathrm{c}}$ values within normal limits suggest that optimal regulation might restore the DTHR in humans.

The function of $T$ cells which mediate the DTHR in influenza infections is not clear. In mice these cells were found in the lungs after infection with an influenza A virus, the concentration of cells being correlated with the amount of virus administered [25]. For recovery from the infection, however, the cytotoxic $\mathrm{T}$ cell and natural killer cell are probably more important [9].

Until now it was assumed that the main risks of influenza infection in patients with diabetes mellitus lie in the occurrence of ketoacidosis [4] and secondary bacterial infection [5]. From this study it can be concluded that impaired immune response to the influenza virus itself may contribute to increased morbidity and mortality.

Acknowledgements. This study was funded by a grant from DupharNederland (Amsterdam, The Netherlands). We wish to thank Mr. R. van Beek and Mr. H. van Driel for technical assistance, Prof. Dr. W. E. Erkelens for comments and Mrs. R.S. Engels-Bakker for preparation of the manuscript.

\section{References}

1. Barker WH, Mullooly JP (1982) Pneumonia and influenza deaths during epidemics. Arch Intern Med 142: 85-89

2. Housworth J, Langmuir A (1974) Excess mortality from epidemic influenza 1957-1966. Am J Epidemiol 100: 40-47

3. Watkins PJ, Soler NG, Fitzgerald MG, Malins JM (1970) Diabetic ketoacidosis during the influenza epidemic. Br Med J 4: 89-91

4. Eickhoff TC, Sherman JL, Serfling RE (1961) Observations on excess mortality associated with epidemic influenza. JAMA 176: $776-782$

5. Khurana RC, Younger D, Ryan JR (1973) Charactersistics of pneumonia in diabetics. Clin Res 21: 629

6. Casey JL, Heeter BJ, Klyshevich KA (1977) Impaired response of lymphocytes of diabetic subjects to antigen of Staphylococcus aureus. J Infect Dis 136: 495-496

7. Rayfield EJ, Ault MJ, Keusch GT, Brothers MJ, Nechemias C, Smith $H$ (1982) Infection and diabetes: the case for glucose control. Am J Med 72: 439-450.

8. Masurel N, Laufer J (1984) A one-year study of trivalent influen$\mathrm{za}$ vaccines in primed and unprimed volunteers; immunogenicity, clinical reactions and protection. J Hyg (Lond) 92: 263-276

9. Ennis A (1982) Some newly recognized aspects of resistance against and recovery from influenza. Arch Virol 73: 207-217

10. Versluis DJ, Beyer WEP, Masurel N, Wenting GJ, Weimar W (1986) Impairment of the immune response to influenza vaccination in renal transplant recipients by cyclosporine $\mathrm{A}$, but not by azathioprine. Transplantation 42: 376-379

11. Ortbals DW, Liebhaber H, Presant CA, Van Amburg A, Lee JY (1977) Influenza immunisation of adult patients with malignant diseases. Ann Intern Med 87: 552-557

12. Gross PA, Lee H, Wolff JA, Hall CB, Minnefore AB, Lazicki ME (1978) Influenza immunization in immunosuppressed children. J Pediatr 92: 30-35 
13. Phair J, Kaufman CA, Bjornson A, Adams L, Linneman C (1978) Failure to respond to influenca vaccine in the aged; correlation with B-cell number and function. J Lab Clin Med 92: 822-828

14. Berlin BS, McQueen JL, Minuse E, Davenport FM (1963) A method for increasing the sensitivity of the haemagglutination inhibition test with equine influenza virus. Virology 21: 665-666

15. Masurel N, Ophof P, De Jong P (1981) Antibody response to immunization with influenza A/USSR/77 (H1N1) virus in young individuals primed or unprimed for A/New Jersey/76 (H1N1) virus. J Hyg (Lond) 87: 201-209

16. Van der Logt JTM, Van Loon AM, Van der Veen J (1981) Hemadsorption immunosorbent technique for determination of rubella immunoglobulin M antibody. J Clin Microbiol 13: 410-415

17. Sokal JE (1975) Measurement of delayed skin test tesponses. N Engl J Med 293: 501-502

18. Feery BJ, Hartman LJ, Hampson AW, Proietto J (1983) Influenza immunisation in adults with diabetes mellitus. Diabetes Care $6: 475-478$

19. Virelizier J-L, Postlethwaite R, Schild GC, Allison AC (1974) Antibody responses to antigenic determinants of influenza virus hemagglutinin. I. Thymus dependence of antibody formation and thymus independence of immunological memory. J Exp Med 140: 1559-1570

20. Quinion-Debrie MC, Debray-Sachs M, Dardenne M, Chernichow P, Assan R, Bach JF (1985) Anti-islet cellular and humoral immunity, T-cell subsets, and thymic function in type 1 diabetes. Diabetes 34: 373-379

21. Lederman MM, Schifman G, Rodman HM (1981) Pneumococcal immunization in adult diabetics. Diabetes 30: 119-121

22. Versluis DJ, Beyer WEP, Masurel N, Weimar W (1985) Influenza vaccination in dialysis and transplant patients. Antiviral Res Suppl. 1: 289-292

23. Plouffe JE, Silva J, Fekety R, Allen JL (1978) Cell mediated immunity in diabetes mellitus. Infect Immun 21: 425-429

24. Mahmoud AAF, Rodman HM, Mandel MA, Warren KS (1976) Induced and spontaneous diabetes mellitus and suppression of cell-mediated immunologic responses. J Clin Invest 57:362-367

25. Leung KN, Ada GL (1980) Cells mediating delayed type hypersensitivity in the lungs of mice infected with an influenza $A$ virus. Scand J Immunol 12: 393-400

Received: 10 November 1986

and in revised form: 6 April 1987

Dr. R.J.A. Diepersloot

Department of Virology

Erasmus University Rotterdam

P.O. Box 1738

NL-3000 DR Rotterdam

The Netherlands 